\title{
Evaluation of Various Factors Which Motivate Children in Ashram Schools of Central India Region to Consume Tobacco Products
}

\author{
Priyanka Sharma ${ }^{1}$, Ritesh Kalaskar ${ }^{2}$
}

\begin{abstract}
Background: Tobacco is consumed in myriad forms in India. The rural population has to bear the brunt of smokeless tobacco products. This leads to several complications. More so, among the rural population, this habit comes into practice at a very young age.

Aims and objectives: To determine the prevalence of consumption of tobacco products among young adolescents, at the same time to evaluate the psychological motivation factors for the same.

Materials and methods: A sample of 2,000 students of the ashram schools was given a detailed questionnaire which included the questions regarding accessibility, liking, source of motivation, and fear of health hazards.

Statistical analysis: The statistical analysis was done using the Statistical Package for the Social Science (SPSS version 22, Armonk, NY: IBM Corp). Depending on the nature of the data, descriptive statistics were performed to assess the prevalence of tobacco consumption and motivational factors associated with it.

Results: The prevalence of tobacco consumption among children was $37.2 \%$. Fifty-one percent of the tobacco users consumed kharra (a mixture of tobacco, lime, areca nut). Forty percent of the tobacco users began using tobacco after the age of 10 years. For $65 \%$ of the individuals' tobacco products were easily accessible.

Conclusion: With the findings of the study, it can be concluded that the easy accessibility to the products in the rural areas is responsible for the children to indulge in such a harmful habit.

Clinical significance: This study focused on the factors that motivate the school-going children in the ashram schools to consumption of various tobacco products. This can give a clear insight as to what measures need to be taken to curb such a problem.

Keywords: Access, Cancer, Motivation, Tobacco.

International Journal of Clinical Pediatric Dentistry (2021): 10.5005/jp-journals-10005-1977
\end{abstract}

\section{INTRODUCTION}

Tobacco is an easily accessible and legally available addictive substance. It contributes to premature death and long-term suffering. It is a major risk factor for cardiovascular diseases, chronic obstructive pulmonary diseases, cancers, and oral diseases..$^{1-3}$ Onethird of the total global burden of oral cancer is predominantly attributed to a high prevalence of tobacco consumption in India. Tobacco is consumed in myriad forms in India. Dry tobacco areca nut preparations, such as gutkha, paan masala, and mawa, are also popular in many parts of the country. ${ }^{4}$ Furthermore, oral tobacco such as mishri, gul, and gudakhu is widely used for topical applications on teeth and gums. ${ }^{5}$ Smokeless tobacco is consumed predominantly by chewing in form of pan, pan-masala or gutkha, and mishri. ${ }^{6,7}$

In studies from India, the mean age of initiation to tobacco use varies between 8 years and 15 years. ${ }^{8-10}$ Many family characteristics have been shown to influence adolescent tobacco use. Low family income, low parental education, and living in single-parent families have been found to predict tobacco use in American adolescents. ${ }^{11}$ Adolescents can be protected from such habits by family factors such as high levels of connectedness, monitoring, and parental punishment. ${ }^{12-15}$ The Global Youth Tobacco Survey (GYTS) (2000$2004)^{16}$ is the first national survey of tobacco use among adolescents in India. It reported the prevalence of use of tobacco in any form to be $25.1 \%$. In replications of the GYTS in 2006 and 2009, about 14\%

\footnotetext{
1,2Department of Pediatric and Preventive Dentistry, Government Dental College, Nagpur, Maharashtra, India
}

Corresponding Author: Priyanka Sharma, Department of Pediatric and Preventive Dentistry, Government Dental College, Nagpur, Maharashtra, India, Phone: +91 9960874550, e-mail: drpriyankasharma32@gmail.com

How to cite this article: Sharma P, Kalaskar R. Evaluation of Various Factors Which Motivate Children in Ashram Schools of Central India Region to Consume Tobacco Products. Int J Clin Pediatr Dent 2021;14(4):554-557.

Source of support: Nil

Conflict of interest: None

(13.7\% in 2006 and $14.6 \%$ in 2009) of students aged 13 to 15 years reported using tobacco in any form. ${ }^{8,9}$

Global Adult Tobacco Survey 2 (GATS 2$)^{17}$ was carried out in all the 30 states of India and the two union territories of Chandigarh and Puducherry from August 2016 to February 2017. According to this survey, the most commonly used tobacco product in India is khaini, tobacco, lime mixture, which is used by every ninth adult (11.2\%). The second commonly used tobacco product is beedi, smoked by $7.7 \%$ of adult Indians. Gutkha, a flavored tobacco, lime, areca nut mixture, ranks third (6.8\%) and betel quid with tobacco ranks fourth (5.8\%). 
Though studies have reported prevalence and factors associated with the initiation of adolescent tobacco use in India, there is little information available on the psychosocial correlates of tobacco use among adolescents. The present study was undertaken to determine the prevalence of tobacco use among children in the ashram schools of Gadhchiroli district which is in a remote area in the central India region and to evaluate the pattern of use and psychosocial correlation.

\section{Materials and Methods}

The study was conducted by the department in the regular dental check-up camps conducted by the institution. It consisted of a detailed questionnaire for the ashram school students. The questionnaire consisted of questions regarding the availability of products, their frequency of consumption, the cost and efforts required to acquire these products. It also consisted of questions regarding motivation factors for the consumption of the products. Age at which, the first time the product was consumed was also determined. This gave us an outlook as to how severe and deeprooted this problem was.

The study was conducted in ashram schools of the Gadhchiroli district, with a sample size of 2,000 children. The detailed questionnaire that was prepared in English as well as in vernacular language (Marathi) was given to the students. The volunteers for the study, blind to its outcome assisted the children with any doubts regarding any question.

We gathered the basic demographic data of the children. All the duly filled forms were carefully collected and the data were then entered in the excel sheets and further it was evaluated using SPSS version 22.

\section{Results}

The statistical analysis was done using the Statistical Package for the Social Science (SPSS version 22, Armonk, NY: IBM Corp). Depending on the nature of the data, descriptive statistics were performed to assess the prevalence of tobacco consumption and motivational factors associated with it. A total of 2,000 participants constituted the study sample. Among them, $53 \%(n=1,061)$ were males and $47 \%$ $(n=939)$ were females. The age of the study population ranged from 11 to 17 years, with the mean age being $15.42 \pm 3.1$. The prevalence of tobacco/gutkha consumption among the ashram children in the Gadhchiroli district was $37.3 \%(n=746)$ as depicted in Table 1. Among 2,000 study participants, $62.7 \%(n=1,254)$ of them denied consuming any form of tobacco/gutkha.

Table 2 shows the type of tobacco products consumed by the participants. Among these, 51.2\% of them consumed kharra. Table 3 depicts the age at which the participants first started the consumption of these products. It was observed that 405 of them started the consumption of these products after the age of 10 years.

The study population who consumed tobacco $(n=746)$ was asked various questions as to what motivated them to consume/stop tobacco. Table 4 summarizes the responses to all those questions. The motivational factors were identified under

Table 1: Prevalence of tobacco consumption

\begin{tabular}{ll}
\hline Tobacco consumption & Frequency $(\%)(N=2,000)$ \\
\hline Yes & $746(37.3)$ \\
No & $1,254(62.7)$ \\
\hline
\end{tabular}

Table 2: Percentage of type of tobacco product consumption

\begin{tabular}{ll}
\hline Type of tobacco product & Frequency $(\%)$ \\
\hline Kharra & $382(51.2)$ \\
Betelnut & $67(9)$ \\
Sweet supari & $239(32)$ \\
Any other & $58(7.8)$ \\
Total & $746(100)$ \\
\hline
\end{tabular}

Table 3: Age of first consumption of tobacco

\begin{tabular}{ll}
\hline Age & Frequency $(\%)$ \\
\hline $3-5$ years & $139(18.6)$ \\
$5-7$ years & $211(28.3)$ \\
$7-10$ years & $98(13.1)$ \\
After 10 years & $298(40)$ \\
Total & $746(100)$ \\
\hline
\end{tabular}

the following domains: Liking for tobacco products, source of motivation, accessibility to tobacco products, cost, and fear of health hazards.

\section{Discussion}

Gadhchiroli district is located in the eastern-most part of Maharashtra adjoining the states of Chhattisgarh and Andhra Pradesh. Ninety-three percent of the district's population lives in rural and tribal areas. ${ }^{18}$ The district has been seriously affected by Maoist activities for the past 25 years. As the majority of the population resides in the rural and tribal areas, the children are sent away for studying in the ashram schools. Being affected by Maoists activity, this region is comparatively non-accessible to the local authorities and hence, educational aids are difficult to reach to this community. According to GATS $2{ }_{1}^{17} 26.6 \%$ of all adults currently use tobacco in any form in the state of Maharashtra. It has been also reported that the prevalence of tobacco use among persons aged 15 to 17 years has increased from $2.9 \%$ in GATS 1 to $5.5 \%$ in GATS $2 .{ }^{17}$

In the present study, the prevalence of tobacco and gutkha consumption came out to be $37.3 \%$ among the ashram school children. What makes this finding unique is that the study population was young adolescents. A previous study for the same region recorded a prevalence of $50.43 \%$ with the highest prevalence in tribal (59.2\%) and lowest prevalence in urban areas (26.73\%). The mean age of the study population was 29.5 years. ${ }^{19}$ Such a high prevalence rate in this particular region calls for immediate action from the government in the form of policymaking and various reforms.

Of the 746 study participants who consumed tobacco, it was seen that $51.2 \%$ of them consumed kharra, followed by sweet supari (32\%). Kharra is a tobacco product with a mixture of lime and other flavored ingredients and is a product that belongs to this region. The ready availability of this product is the most common reason for its addiction. In a tribal and rural area like Gadhchiroli, it can be seen as a local household product. Previous studies have stated that the prevalence of chewable tobacco consumption was distinctly higher in Central and Eastern India, and in the Northeastern states. ${ }^{5}$ It was observed in previous studies that consumption of the chewable form of tobacco was highest in the less educated, poor, and among tribal people. ${ }^{4}$ 
Table 4: Motivational factors for tobacco consumption

\begin{tabular}{|c|c|}
\hline Motivational factors & $\begin{array}{l}\text { Frequency (\%) }[n=746 \\
(100)]\end{array}$ \\
\hline \multicolumn{2}{|l|}{ Liking for the product } \\
\hline \multicolumn{2}{|c|}{$\begin{array}{l}\text { - Did you like it when you first } \\
\text { consumed it? }\end{array}$} \\
\hline a. Yes & $358(48)$ \\
\hline b. No & $388(52)$ \\
\hline \multicolumn{2}{|c|}{ - Did you feel like eating often? } \\
\hline a. Yes & $381(51)$ \\
\hline b. No & 365 (49) \\
\hline \multicolumn{2}{|l|}{ Source of motivation } \\
\hline \multicolumn{2}{|c|}{$\begin{array}{l}\text { - Where did you first get motivation to } \\
\text { consume this stuff? }\end{array}$} \\
\hline a. Parents & $112(15)$ \\
\hline b. Siblings & $52(7)$ \\
\hline c. Friends & $567(76)$ \\
\hline d. Teachers & $15(2)$ \\
\hline \multicolumn{2}{|l|}{ Accessibility } \\
\hline \multicolumn{2}{|c|}{ - Was the access to the products easy? } \\
\hline a. Yes & $485(65)$ \\
\hline b. No & $261(35)$ \\
\hline \multicolumn{2}{|c|}{$\begin{array}{l}\text { Where do you get access to these } \\
\text { products? }\end{array}$} \\
\hline a. Local vendors & $609(81.6)$ \\
\hline b. Friends & $125(16.7)$ \\
\hline c. Home & $12(1.6)$ \\
\hline \multicolumn{2}{|c|}{ Cost } \\
\hline \multicolumn{2}{|c|}{$\begin{array}{l}\text { - Are these products available to you } \\
\text { free of cost? }\end{array}$} \\
\hline a. Yes & $60(8.1)$ \\
\hline b. No & $686(91.9)$ \\
\hline \multicolumn{2}{|c|}{$\begin{array}{l}\text { Have you ever stolen money to buy } \\
\text { these products? }\end{array}$} \\
\hline a. Yes & $41(5.5)$ \\
\hline b. No & 705 (94.5) \\
\hline \multicolumn{2}{|c|}{ Fear of health hazards } \\
\hline \multicolumn{2}{|c|}{$\begin{array}{l}\text { Do your parents know that you } \\
\text { consume these products? }\end{array}$} \\
\hline a. Yes & $157(21)$ \\
\hline b. No & $207(27.7)$ \\
\hline c. I don't know & $382(51.3)$ \\
\hline \multicolumn{2}{|c|}{$\begin{array}{l}\text { - Did your parents stop you from } \\
\text { consuming? }\end{array}$} \\
\hline a. Yes & $261(35)$ \\
\hline b. No & $485(65)$ \\
\hline \multicolumn{2}{|c|}{$\begin{array}{l}\text { Do you know consumption of tobacco } \\
\text { and other products causes cancer? }\end{array}$} \\
\hline a. Yes & $634(85)$ \\
\hline b. No & $112(15)$ \\
\hline
\end{tabular}

The present study also reveals that $40 \%$ of the tobacco product consumers started using these products after 10 years of age, whereas $28.3 \%$ of them began to consume when they were in the age group of 5 to 7 years, followed by 18.6 and $13.1 \%$ who began to consume in the age groups of 3 to 5 and 7 to 10 years, respectively. In studies from India, the mean age of initiation to tobacco varied between 8 years and 15 years. $8,10,12$ Similar to the present study, many Indian studies, particularly from states reporting higher prevalence, have observed a younger age of onset, e.g., of 10 years or less ${ }^{16}$ which is also similar to studies in countries with high prevalence among adolescents. ${ }^{11,20}$ Looking at the age at which the first consumption of tobacco products started is very alarming. One thing has to be kept in mind younger the population, the more deep-rooted the problem is.

Furthermore, liking tobacco products was also determined through the questionnaire. It was observed that among the tobacco users, $48 \%$ of them liked it, whereas $52 \%$ disliked it on first consumption. Still, both the groups continued the consumption of these products. Regarding the frequency of consumption, it revealed that $51 \%$ of them liked eating tobacco often, although $49 \%$ of them did not. Still, they did not discontinue the habit.

The first source of motivation to consume tobacco came from friends for $76 \%$, from parents for $15 \%$, from siblings and teachers for 7 and 2\%, respectively. This quite aptly describes the current situation for these children, where the motivation for consumption of such harmful products comes from friends and family and even teachers. Hence, drastic measures need to be taken to curb this problem completely. Parents and teachers are often considered as role models for a child and hence, stricter rules and policies and health awareness should be generated to educate the adults in the community. The finding in this presented can be corroborated by the findings from a small study conducted in the rural areas of Indian states of Gujrat, Tamil Nadu, and Karnataka where one-third to one-half of children under the age of 10 years experimented with smokeless tobacco, imitating parents, grandparents, other elders in the family, or peers. ${ }^{20}$

Accessibility plays a major role in encouraging people to consume more tobacco. It revealed that $65 \%$ of the consumers' tobacco products were easily accessible, whereas $35 \%$ of them denied easy accessibility to tobacco products. The majority of the study population, i.e., $81.6 \%$ reported that access to tobacco products was through local vendors, followed by $16.7 \%$ reported through friends and $1.6 \%$ reported that they find access to tobacco products at their home themselves. Easy accessibility of these products from the local vendors makes uprooting this problem even more difficult. The responsibility falls on the local authorities and the government. The products are not available free of cost, but they are sold at a very cheap price. At one instance, we even came across a vendor just outside the school. The children get a monthly scholarship from the government to sustain their life. It falls on the responsibility of the teachers, hostel wardens, and peers to assess that this money is spent wisely and not on these habits.

In the present study, around $21 \%$ of tobacco users, the parents were aware of their children's habits. The majority of the study population were young adolescents and hence, psychologically it is difficult to uproot a deep-rooted habit. Moreover, the children accepted that they were not stopped by their parents for consumption of these products. The most astounding finding of this study was that $85 \%$ of the study participants were aware of the harmful effects and hazards of tobacco usage. According to GATS 2, of the smokeless tobacco users $94.0 \%$ agreed that it causes serious illness, $92.3 \%$ agreed that it causes oral cancers, and $88.9 \%$ agreed that it causes other dental diseases. ${ }^{17}$ 
Tobacco use has been associated with increased poverty in India and other developing nations. ${ }^{18,21}$ A stricter tobacco control policy by the government could be a potential strategy to decrease public expenditure. Improvement in public healthcare and reduction in healthcare expenditure can be alleviated using such policies. The tobacco industry is a source of revenue for the government and provides employment. However, Jha and Chaloupka ${ }^{22}$ found that a $10 \%$ increase in tobacco taxation may increase government revenues by $7 \%$. Similarly, job losses from stricter tobacco control can be countered by new job opportunities in other industries.

Although the Cigarettes and Tobacco $\mathrm{Act}^{23}$ disallows the sale of tobacco in any form to persons under 18 years and within 100 yards of educational institutions, we observed the sale of these products being carried out right outside the ashram schools. To curb such a deep-rooted problem, health workers and NGOs need to reach out to these populations. Methods of communication that can be used to deliver messages among the population regarding hazards of tobacco use may include personal communication, films, posters, newspaper articles, folk dramas, radio programs, exhibits, group meetings, and cessation camps. The message should be given to the population as interactively as possible. The health messages should be personally relevant to the consumer and tailored to his/ her beliefs and lifestyle, including the prevalent tobacco habits in the area.

Some of the main messages that can be delivered are:

- Tobacco does not cause toothache but causes oral cancer.

- Tobacco weakens the heart and makes you die earlier.

- Elders are role models for children and if they consume tobacco, children get influenced by it.

- Tobacco usage is harmful at the same time expensive.

- Premature death of parents due to ill effects of tobacco, deprive the children of social support.

\section{Conclusion}

It can be concluded that easy accessibility to tobacco products in the rural areas is a major motivational as well as a contributing factor to the indulgence of young adolescents in such a harmful deleterious habit.

\section{References}

1. Sauvaget $C$, Ramadas $K$, Thara S. Tobacco chewing in India. Int J Epidemiol 2008;37(6):1242-1245. DOI: 10.1093/ije/dyn097.

2. Zarocostas J. WHO lists "best buys" for cutting deaths from noncommunicable disease. BMJ 2011;342(apr27 1):2648. DOI: 10.1136/ bmj.d2648.

3. Sarkar BK, Reddy KS. Priorities for tobacco control research in India. Addiction 2012;107(12):2066-2068. DOI: 10.1111/j.13600443.2012.03942.x.

4. Rooban T, Elizabeth J, Umadevi KR, et al. Sociodemographic correlates of male chewable smokeless tobacco users in India: a preliminary report of analysis of National Family Health Survey, 2005-2006. Indian J Cancer 2010;47(5):91-100. DOI: 10.4103/0019-509X.63865.
5. Rani $\mathrm{M}$, Bonu $\mathrm{S}$, Jha $\mathrm{P}$, et al. Tobacco use in India: prevalence and predictors of smoking and chewing in a national cross sectional household survey. Tob Control 2003;12(4):4. DOI: 10.1136/tc. 12.4.e4.

6. Gupta PC, Ray CS. Smokeless tobacco and health in India and South Asia. Respirology 2003;8(4):419-431. DOI: 10.1046/j.14401843.2003.00507.x.

7. Dobe M, Sinha DN, Rahman K. Smokeless tobacco use and its implications in WHO South East Asia Region. Indian J Public Hlth 2006;50(2):70-75.

8. Jayakrishnan R, Geetha S, Binukumar B, et al. Self-reported tobacco use, knowledge on tobacco legislation and tobacco hazards among adolescents in rural Kerala State. Indian J Dent Res 2011;22(2):195-199. DOI: 10.4103/0970-9290.84280.

9. Philip PM, Neetu AP, Binukumar B, et al. Evaluation of a tobacco control programme to reduce tobacco use among school children in Kerala. Asian Pac J Cancer Prev 2013;14(6):3455-3459. DOI: 10.7314/ apjcp.2013.14.6.3455.

10. Bhojani UM, Chander SJ, Devadasan N. Tobacco use and related factors among pre-university students in a college in Bangalore, India. Natl Med J India 2009;22(6):294-297.

11. Johnston LD, O'Malley PM, Miech RA, et al. Monitoring the future national results on drug use: 1975-2013: overview, key findings on adolescent drug use. Ann Arbor: Institute for Social Research, The University of Michigan; 2014. pp. 42-43.

12. Pradeepkumar AS, Mohan S, Gopalakrishnan P, et al. Tobacco use in Kerala: findings from three recent studies. Natl Med J India 2005;18(3):148-153.

13. Sinha DN, Gupta PC, Pednekar MS. Tobacco use among students in the eight North-Eastern states of India. Indian J Cancer 2003;40(2):43-59.

14. Pednekar MS, Gupta PC. Tobacco use among school students in Goa, India. Indian J Public Health 2004;48(3):147-152.

15. Kandel DB, Kiros GE, Schaffran C, et al. Racial/ethnic differences in cigarette smoking initiation and progression to daily smoking: a multilevel analysis. Am J Public Health 2004;94(1):128-135. DOI: 10.2105/ajph.94.1.128.

16. Gajalakshmi V, Kanimozhi CV. A survey of 24,000 students aged 13-15 years in India: global youth tobacco survey 2006 and 2009. Tob Use Insights 2010;3:23-31. DOI: 10.1177/1179173X1000300001.

17. Tata Institute of Social Sciences (TISS), Mumbai and Ministry of Health and Family Welfare, Government of India. Global Adult Tobacco Survey GATS 2 India 2016-17.

18. John R, Sung H, Max W, et al., "Counting 15 Million More Poor in India, Thanks to Tobacco", Tobacco Control, 3 February, 2011 10.1136/tc.2010.040089. http://www.ncbi.nlm.nih.gov/pubmed/ 21292807.

19. Sawalkar S, Deshmukh M, Kalkonde Y, et al. Tobacco vs development private spending on tobacco in gadchiroli district. Econo Polit Weekly 2013;48:19-23.

20. Krishnamurthy $S$, Ramaswamy $R$, Trivedi $U$, et al. Tobacco use in rural Indian children. Indian Pediatr 1997;34(10):923-927.

21. de Beyer J, Lovelace $C$, Yürekli A. Poverty and tobacco. Tob Control 2001;10(3):210-211. DOI: 10.1136/tc.10.3.210.

22. Jha P, Chaloupka FJ. The economics of global tobacco control. BMJ (Clinical Research Ed) 2000;321(7257):358-361. DOI: 10.1136/ bmj.321.7257.358.

23. Reddy KS, Gupta PC, ed. Report of tobacco control in India. New Delhi: Ministry of Health and Family Welfare, Government of India; 2004. pp. 61-63. 